\title{
Hybrid compounds based on the pyrrolidine-2,5-dione scaffold as candidates for new wide spectrum anticonvulsant agents
}

Michał Abram ${ }^{1 *}$, Marcin Jakubiec ${ }^{1}$, Anna Rapacz², Bartiomiej Szulczyk ${ }^{3}$, Krzysztof Kamiński $^{1}$
1Department of Medicinal Chemistry, Faculty of Pharmacy, Jagiellonian University Medical College, Krakow, Poland,
2Department of Pharmacodynamics, Faculty of Pharmacy, Jagiellonian University Medical College, Krakow, Poland,
${ }^{3}$ Department of Drug Technology and Pharmaceutical Biotechnology, Medical University of Warsaw, Banacha 1, 02-097 Warsaw, Poland

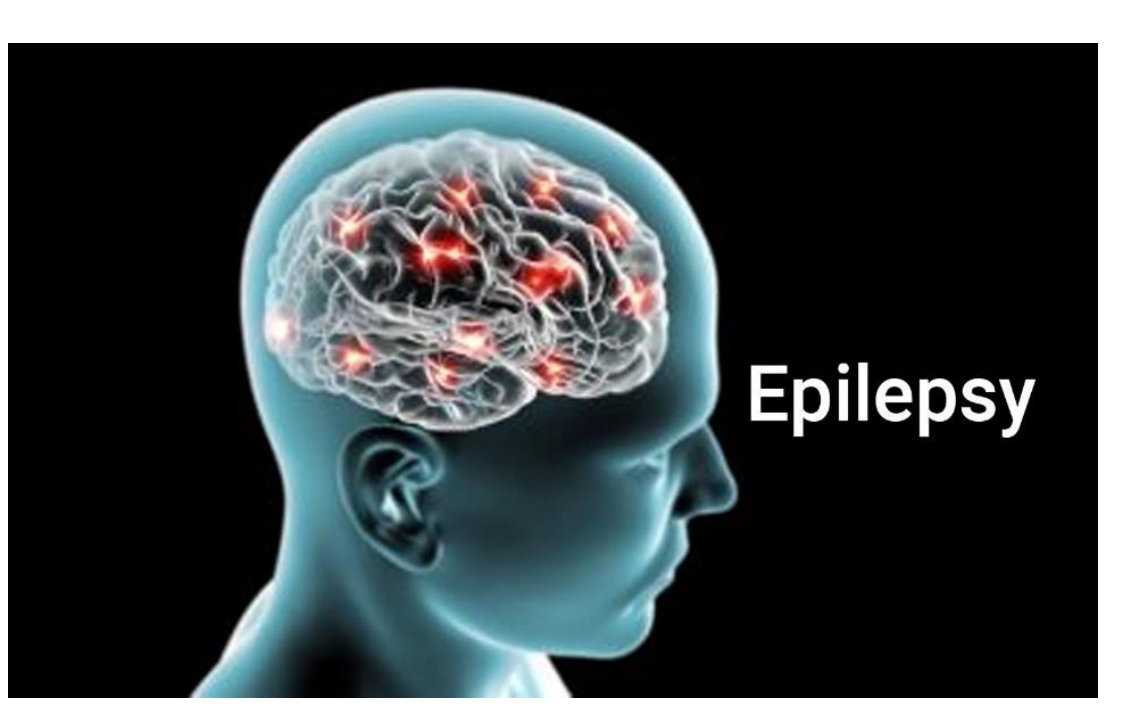

Affects $1 \%$ of world population

About one-third of the patients with epilepsy

develop resistance to antiepileptic drugs (AEDs)

The prevalence increases with the age

\section{Introduction}

In recent years, a considerable interest has been generated in designing new multi-target compounds as they have been proven to be advantageous in the treatment of multifactorial diseases (characterized by complex pathomechanism) and also have been proven to alleviate health conditions linked to drug resistance. ${ }^{1,2}$ Epilepsy, which is recognized as the most common and debilitating neurological disorder, without any doubt, fulfills both the aforementioned criteria. Keeping the requirements of multi-target drugs in mind and with the aim of obtaining new highly effective broad-spectrum anticonvulsants, in the previous studies, we developed integrated hybrid molecules derived from the pyrrolidine-2,5-dione ring. . $^{3-6}$

These compounds were designed by applying the fragment-based approach therefore, they merge on the common structural framework the chemical fragments of three chemically and pharmacologically diversified AEDs such as ethosuximide (ETX, effective especially in pentylenetetrazole-induced seizure model (PTZ)), levetiracetam (LEV, effective in $6 \mathrm{~Hz}$ model), and lacosamide (LCS, active in both maximal electroshock (MES) and $6 \mathrm{~Hz}$ seizure models). As a result, the process of hybridization yielded hybrid compounds with potent broadspectrum anticonvulsant activity joining the pharmacological properties of all aforementioned AEDs. (Fig. 1.)
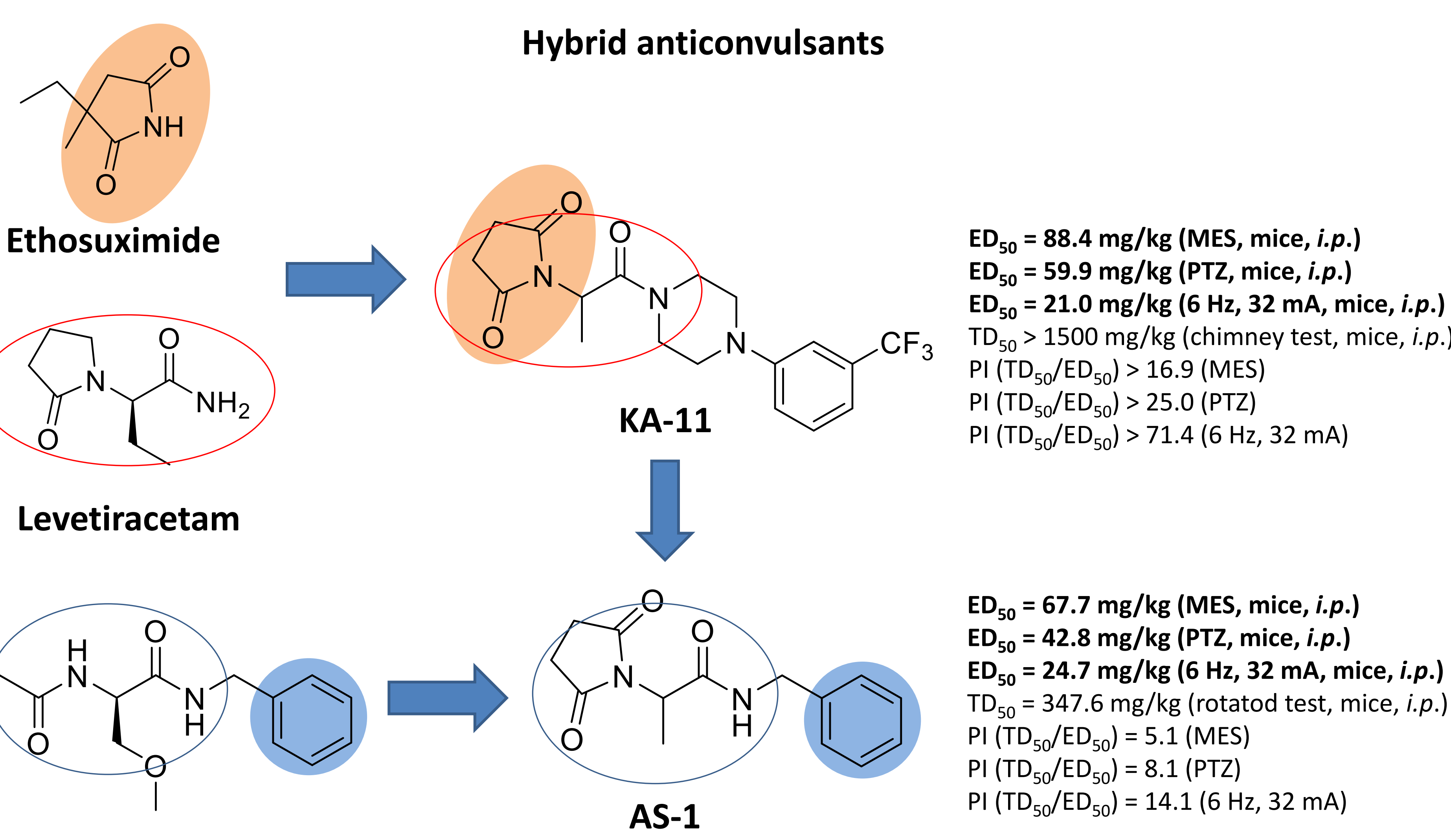

Lacosamide

AS-1

Anticonvulsant activity

The anticonvulsant activity of hybrid compounds was assessed using the maxima electroshock seizure test (MES), the subcutaneous pentylene-tetrazole seizure test (PTZ), and the $6 \mathrm{~Hz}$ seizure model (32 $\mathrm{mA}$ and $44 \mathrm{~mA}$ ), in mice after intraperitoneal injection.

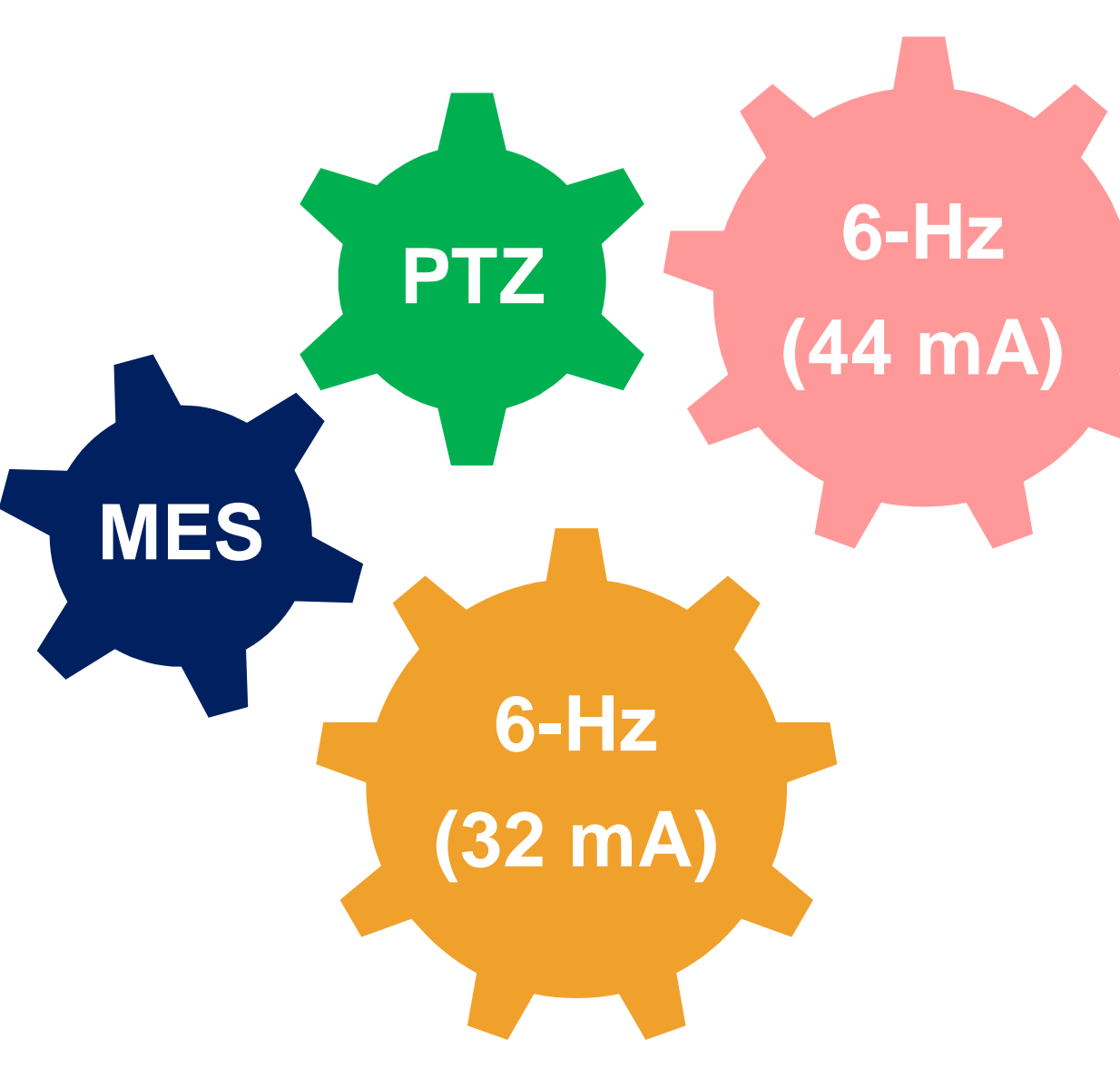

The AS hybrids demonstrated broad-spectrum anticonvulsant activity in the preclinical studies (MES, PTZ, $6 \mathrm{~Hz} 32 \mathrm{~mA}$ and $44 \mathrm{~mA}$ ). The most potent was AS-34 with following pharmacological parameters (time point of $30 \mathrm{~min}$.)

\begin{tabular}{|c|c|c|}
\hline & AS-34 & VPA \\
\hline $\mathrm{ED}_{50}(\mathrm{MES})(\mathrm{mg} / \mathrm{kg})$ & $\mathbf{4 0 . 5}$ & 252.7 \\
\hline $\mathrm{ED}_{50}(\mathrm{PTZ})(\mathrm{mg} / \mathrm{kg})$ & $\mathbf{5 0 . 2}$ & 239.4 \\
\hline $\mathrm{ED}_{50}(6 \mathrm{~Hz}, 32 \mathrm{~mA})(\mathrm{mg} / \mathrm{kg})$ & $\mathbf{7 . 6}$ & 130.6 \\
\hline $\mathrm{ED}_{50}(6 \mathrm{~Hz}, 44 \mathrm{~mA})(\mathrm{mg} / \mathrm{kg})$ & $\mathbf{6 9 . 5}$ & 183.1 \\
\hline $\mathrm{TD}_{50}($ rotarod test) $(\mathrm{mg} / \mathrm{kg})$ & $>500$ & 430.7 \\
\hline
\end{tabular}

AS-34 revealed more potent protection (in each seizure model) and was safer in the rotarod test then broad-spectrum AED - valproic acid (VPA).

Electrophysiological studies

We determined the influence of AS-34 on fast voltage-gated sodium channels in rat prefrontal cortex pyramidal neurons (at a concentration of $100 \mu \mathrm{M}$ ) using the patch-clamp technique. ${ }^{7}$ AS-34 inhibited significantly maximal amplitude of sodium currents to $0.6 \pm 0.06$ as compared to control. Importantly, it was possible to obtain partial wash-out $(0.79 \pm 0.06, n=6)$, which proves that the effect was reversible. The averaged results are shown in Fig. 3.
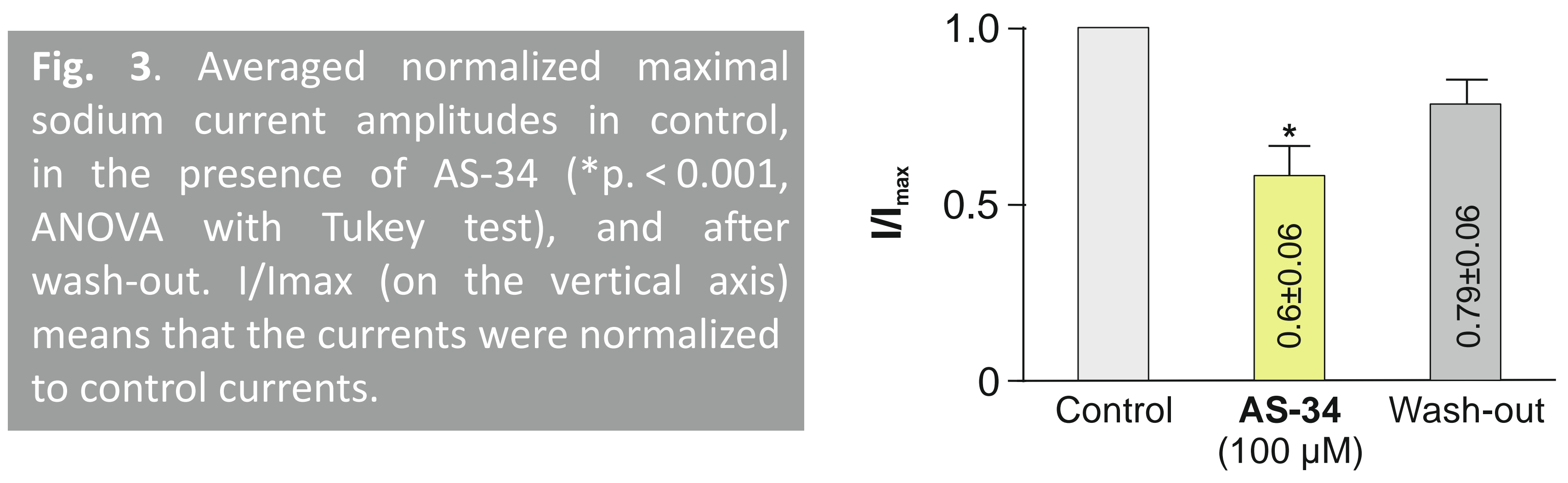

\section{In vitro radioligand binding studies}

Compound AS-34 demonstrated broad-spectrum anticonvulsant activity in the preclinical studies, which most likely reflects its multiple sites of action. We performed binding assays for several voltage-gated or ligand-gated channels and GABA-transporter as the most common molecular targets for anticonvulsants. As a result, AS-34 revealed significant binding toward L-type $\mathrm{Ca}^{2+}$ channel (three sites). Furthermore, the L-type calcium ion channel cell-based flux studies revealed that AS-34 possesses an antagonist activity. Compound AS-34 did not interact with $\mathrm{N}$-type $\mathrm{Ca}^{2+}$ channel, GABA transporter, and notably potassium channel (hERG) at a concentration of $100 \mu \mathrm{M}$, thus it has a low risk of cardiac toxicity.

\section{Aim of studies}

Considering the anticonvulsant properties of the aforementioned hybrid molecules and with the aim of obtaining compounds with greater ability to protect against seizures using the MES, $6 \mathrm{~Hz}(32 \mathrm{~mA})$, and PTZ seizure models, as well as to find substances that are effective in the $6 \mathrm{~Hz}(44 \mathrm{~mA})$ model of drug-resistant epilepsy, in this study, we developed a new AS series of hybrid compounds with the pyrrolidine-2,5-dione as a core structure. The process of molecular hybridization involved both known AEDs as well as other anticonvulsant active compounds.
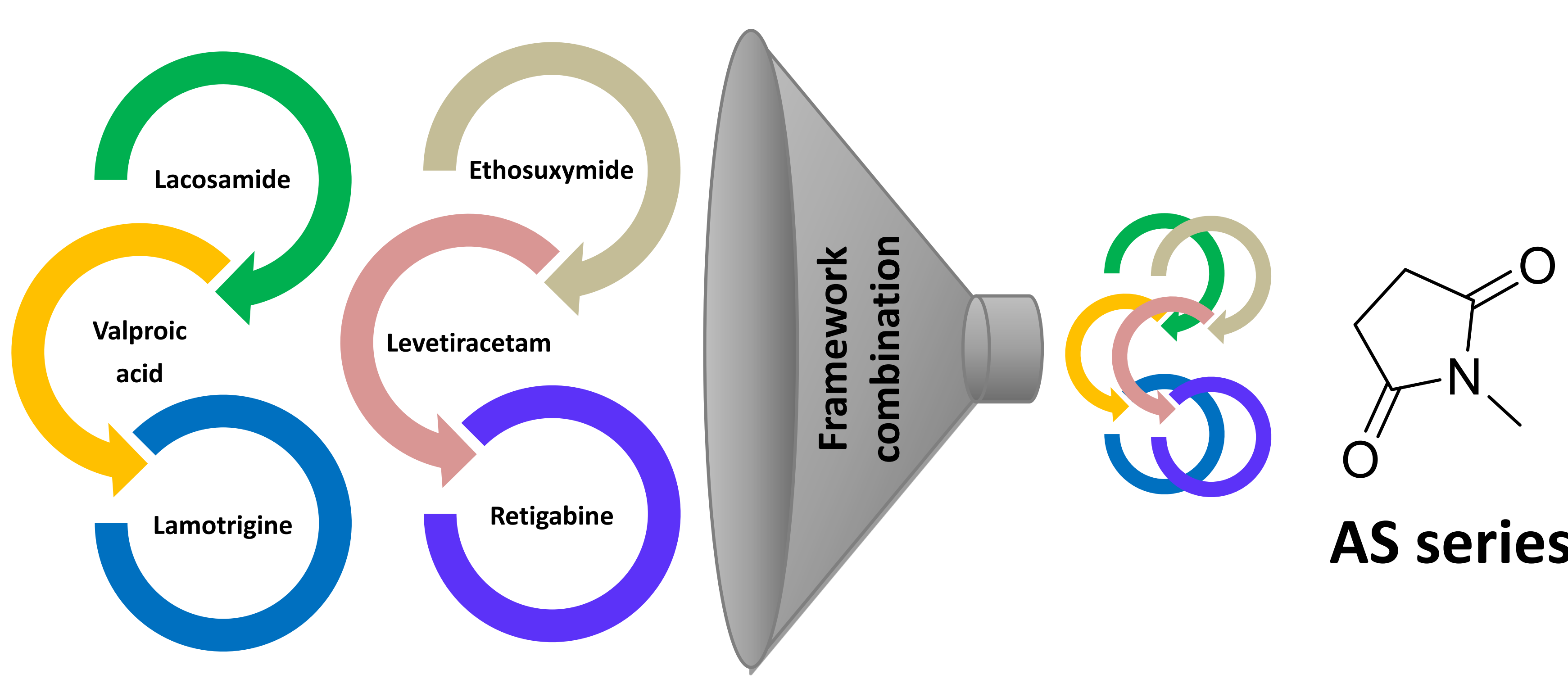

\begin{tabular}{|c|c|c|}
\hline binding studies & source & $\begin{array}{c}\% \text { inhibition of } \\
\text { control specific } \\
\text { binding }\end{array}$ \\
\hline $\mathrm{Na}^{+}$channel (site 2$)$ & rat cerebral cortex & 38.19 \\
\hline $\mathrm{N}$-type $\mathrm{Ca}^{2+}$ (antagonist radioligand) & rat cerebral cortex & 1.1 \\
\hline $\begin{array}{c}\text { L-type } \mathrm{Ca}^{2+} \\
\text { (dihydropyridine site, antagonist radioligand) }\end{array}$ & rat cerebral cortex & 82.3 \\
\hline L-type $\mathrm{Ca}^{2+}$ (diltiazem site, antagonist radioligand) & rat cerebral cortex & 68.5 \\
\hline L-type $\mathrm{Ca}^{2+}$ (verapamil site, antagonist radioligand) & rat cerebral cortex & 57.1 \\
\hline GABA transporter (antagonist radioligand) & rat cerebral cortex & 0.3 \\
\hline GLYT1 (antagonist radioligand) & rat cerebral cortex & 23.0 \\
\hline potassium channel (hERG) & $\begin{array}{l}\text { human recombinant } \\
\text { (HEK-293 cells) }\end{array}$ & 4.54 \\
\hline functional studies & & $\begin{array}{c}\% \text { inhibition of } \\
\text { control agonist } \\
\text { response }^{\mathrm{a}}\end{array}$ \\
\hline L-type $\mathrm{Ca}^{2+}$ (antagonist radioligand) & $\begin{array}{l}\text { human recombinant } \\
\text { (HEK-293 cells) }\end{array}$ & 85 \\
\hline \multicolumn{3}{|c|}{$\begin{array}{l}\text { Results showing activity higher than } 50 \% \text { are considered to represent significant effects of the test compounds; results showing } \\
\text { an inhibition between } 25 \% \text { and } 50 \% \text { are indicative of weak effect; results showing an inhibition lower than } 25 \% \text { are not considere } \\
\text { significant and mostly attributable to variability of the signal around the control level. Binding studies were performed } \\
\text { commercially in Cerep Laboratories (Poitiers, France). }\end{array}$} \\
\hline \multicolumn{3}{|c|}{ References } \\
\hline \multicolumn{3}{|c|}{$\begin{array}{ll}\text { 1) Talevi, A. Front. Pharmacol. 2015, 6, 205. } & \text { (5) Kamiński, K. et al. Bioorg. Med.. Chem. 2015, 23, 2548-2561. } \\
\text { 2) Bansal, Y.; Silakari, O. Eur. J. Med. Chem. 2014, 76, 31-42. } & \text { (6) Kamiński, K. et al. Bioorg. Med. Chem. 2016, 22, 2938-2946. } \\
\text { 3) Abram, M. et al. J. Med. Chem. 2017, 60, 8565-8579. } & \text { (7) Szulczyk, B.; Nurowska, E. Biochem. Biophys. Res. Commun. } \\
\text { 4) Kamiński, K. et al. J. Med. Chem. 2015, 58, 5274-5286. } & \text { 2017, 491, 291-295. }\end{array}$} \\
\hline
\end{tabular}

